\title{
Emergency Remote Teaching Application due to COVID- 19 - A Case Study of the Department of Mathematics (School of Science) at the National and Kapodistrian University of Athens
}

\author{
M. Karaliopoulou, Y. Mavrommatis, G. Menounou, and St. Pantelopoulou
}

\begin{abstract}
The aim of this study was to analyze students' experience of the implementation of emergency distance learning by their department due to the COVID-19 pandemic. The subjects of the study were University students of the department of Mathematics of the National and Kapodistrian University of Athens selected with a convenience sampling technique. A semi-structured questionnaire was used which was distributed online. A total of 391 student responses were collected for analysis. The study's results indicate that students identify some positive characteristics in emergency remote teaching such as: access to recorded video lectures, efficient time management, and comfortable environment. On the other hand, they complain about network instability, lack of technical means and lack of communication in e-learning lessons. It seems that the majority of students preferred courses combining face to face and e-learning methods and evaluated as excellent the synchronous form of distance learning that uses teleconference platforms and digital boards.
\end{abstract}

Keywords - COVID-19, Emergency Remote Teaching (ERT), Greece, Higher Education.

\section{INTRODUCTION}

In response to the coronavirus pandemic, the University of Athens cancelled on-campus lessons on March $11^{\text {th }}$, 2020, activities were resumed remotely, and students and faculty started using online platforms (synchronous and asynchronous). This case study is about the first period of COVID-19, a period of strict confinement.

The remarkable difference between existing distance learning courses before COVID-19 and the emergency remote teaching (ERT) that took place during the period in Greek Universities is the fact that it was not planned and was considered as temporary.

There are some aspects of this kind of learning that clearly distinguish it from distance education [1]. The

\footnotetext{
Submitted on November 4, 2021.

Published on February 16, 2022.

M. Karaliopoulou, National and Kapodistrian University of Athens, Greece.

(e-mail: mkaraliop@math.uoa.gr)

Y. Mavrommatis, National and Kapodistrian University of Athens, Greece.

(e-mail: ymavrom@math.uoa.gr)

G. Menounou, Ministry of Education, Research and Religious Affairs, Greece.

(e-mail: gmenounou@sch.gr).

St. Pantelopoulou, Ministry of Education, Research and Religious Affairs, Greece.

(e-mail: stpantelopoulou@sch.gr).
}

foremost characteristic is the fact that it takes place in a period full of panic and anxiety [2]. Researchers, apart from distinguishing distance education from ERT, try to make clarifications about ERT's evaluation. The adaptation of a typical university course to a steady distance learning one takes six to nine months (including planning, preparation, and development). In extreme circumstances, like COVID19 , priority is given to how fast we can build an educational model that keeps students safe. In general, faculty members do not have the support that they used to have for digital innovations. All in all, ERT courses developed "as soon as possible/asap" have a lack of content quality. Evaluation of ERT should care about students' ideal learning outcomes [3].

The number of affected students according to UNESCO reports [4], [5] equals to $83 \%$ of the world's enrolled students from March 2020 onwards and learning inequalities have widened. Distance education is a wellestablished field which primarily requires efficient planning. It focuses on the learners' needs, it uses state of the art technology, and its value is measured through its content quality. As Bozkurt and Sharma [6] underline "while distance education has always been an alternative and flexible option for learners, emergency remote teaching is an obligation". During a crisis, and there are many to come according to the Civil Protection structures of numerous countries, what came to surface is the need to care not only for teaching and lecturing but also for concern, collaboration, and support. There will be no excuses for future interruptions through any kind of crisis in education (e.g., war, virus, physical catastrophe, hurricane) not to be handled in a planned manner [7]-[9]. There are experts who claim that some of the changes in education caused by COVID-19 will be the "new normal" [10].

The aim of this study is to analyze Greek students' experience of the implementation of ERT by their department due to the COVID-19 pandemic.

\section{LITERATURE REVIEW}

Shim and Lee [11] conducted research in college students that was focused on their satisfaction and dissatisfaction with emergency remote teaching as well as their desired improvement. Their survey was conducted in April 2020, with Korean students already having a four-week ERT on Webex (synchronous teaching). Researchers used a semistructured questionnaire and gathered a total of 393 student responses for analysis. There is a number of positive 
features that students indicated, such as "comfortable educational environments, smooth interactions, and efficient time utilization", while less notable advantages include "social distancing is possible, data that can be recorded can be used, academic achievement, psychological stability, and transportation cost reduction". On the other hand there is a number of negative ones "network instability, unilateral interactions, and reduced concentration" with some minor faults such as "insufficient data provision, dissatisfaction with substitution of assignments, constraints in team projects, reduced academic achievement, unprepared class design, reduced understanding of classes, dissatisfaction with assessment, administrative dissatisfaction, dissatisfaction with relationship formation, and dissatisfaction with the educational environments". Research concludes that "an improved and effective emergency remote teaching system" can be prepared in order to assimilate the achievements of traditional classroom teaching in case of some similar crisis outbreak.

In their paper, Kutluk \& Gulmez [12] examine students' satisfaction with the quality of distance education in Universities' accounting programs. They appreciate the opportunity to work part time and to use multimedia resources for better understanding. On the contrary, most of them lack self-regulation and underline the need for quality programs, good technical infrastructure, efficient course design and teacher training for using such media.

Through their proposals for the evaluation of ERT, researchers [3] reveal what characteristics they think are the most valuable. The media used is almost of no interest. The stakeholder that matters is mostly the student. Thus, his/her learning outcomes, skills, motivation, and engagement are very important. They underline the difficulty of assessing students with ERT systems.

A research in the University of Malaysia, involving 399 students of online learning courses, examined their online learning readiness. The aim was to reveal if demographic factors are related to noteworthy differences, to register experiences and to examine the possibility of continuing to use online learning. Researchers used a scale (Online Readiness Scale-OLRS) with five dimensions as their instrument: self-directed learning, learner control, motivation for learning, computer/ internet self-efficacy and online communication self-efficacy. They added some items to assess respondents' overall learning satisfaction, experience and intention to continue using online learning. Females seem to be more ready than males and more than half of the respondents do not want to continue with online learning in the future. Problems with internet connectivity and difficulty in understanding the content of the subject were revealed. In addition, once more there is evidence that Universities need to enhance academics' online teaching skills [10].

In Spain only 15 percent of Bachelor's Degree students were enrolled in distance education universities on March 11 2020, when the State announced suspension of all faceto-face education activities and three days later a total lockdown. In Madrid over 98 percent of undergraduate students attended face-to-face learning and, all of a sudden, unprepared academic staff had to adjust overnight for distance education. A study that took place at the School of Telecommunication Engineering (Universidad Politécnica de Madrid) revealed the impact of this unplanned change. The research was qualitative (questionnaire for 43 course coordinators) and quantitative (academic records of 43 courses). The research compared the academic results of the students during the COVID-19 pandemic with those of previous years. An increase of academic performance is obvious in the ERT period, which is not dependent on class sizes or delivery modes (synchronous and asynchronous teaching). The paper includes in its literature review section a significant number of cases where academic excellence of the students attending online, or blended learning compared to face-to-face is proved. The research also highlights the fact that academics had to quickly choose between several digital tools of different teaching support capabilities and to balance their workload at the same time [13].

In India [14], COVID-19 affected the higher education system as follows: a. "Destabilized all educational activities", b. "Mixed impact on Academic research and Professional Development", c. "Severely affected the educational assessment system", d. "Reduced employment opportunities". Universities launched many virtual platforms to mitigate the effects (online repositories, ebooks, online teaching/learning materials, educational channels through Direct to Home TV, Radios for students), and students were using popular social media tools like WhatsApp, Zoom, Google meet, Telegram, YouTube live, Facebook live etc. The paper, among others, enlists post COVID-19 trends of Higher Education Institutions (HEIs) and suggests ways for continuing educational activities of HEIs facing the challenges created by COVID-19. Some of these new trends are: 1. "May encourage personalized learning", 2. "Student Attendance may slow down", 3. "National and International student mobility for higher study may be reduced", 4. "Learning with social distancing may continue", 5. "Educational institutions may run with different shifts per day", 6. "May raise the gap between privileged and unprivileged students", 7. "Teaching learning may run with technology", 8. "Assessment system may be changed to new shape", 9. "Demand for Open and Distance Learning (ODL) and online learning may grow", 10. "Blended learning may take the leading role", 11. "Student debt crisis may rise", 12. "Unemployment rate is expected to be increased". Tankar underlines the same basic topics and reveals that one major problem was students' engagement during the e-learning [14], [15].

In the report of OECD [16] one aspect that is highlighted is the major problem that COVID-19 caused to international student flows. As countries shut their borders and universities closed their premises, international students faced countless problems. The major problem from the universities' perspective is their immaturity to deliver instruction and assignments in a new way. All in all, "examinations were affected, causing disruption to students' learning trajectories and progression", "few students considered it as the sole alternative to physical inperson learning", "students lost other benefits of international mobility such as international exposure, access to a foreign job market and networking". The aforementioned caused serious funding problems to 
universities in countries such as Australia, Canada, New Zealand, the United Kingdom and the United States. COVID-19 exposed the fact that "students are unlikely to devote large amounts of time and money to consume online content", since "they go to universities to meet great people, have inspiring conversations with faculty, collaborate with researchers in the laboratory and experience the social life on campus".

\section{THE CONTEXT}

During the case study period (March till June 2020), when distance learning (which was an ERT case) was imposed, all classes were synchronous and asynchronous, but not all of them used the same platforms and processes. In the context of the research, we were not interested in differences between platforms.

The eClass platform (https://eclass.uoa.gr/) was used for the asynchronous eLearning. "The Open eClass platform is a complete Course Management System and it is the solution offered by the Greek Academic Network GUnet to support asynchronous eLearning services. It has been designed with the intention to support the conventional educational process." [17]. Students could also use "Kallipos" (https://repository.kallipos.gr) as an eLearning Service. "The "Kallipos" Repository gathers books, handbooks and learning objects, which were either produced within the framework of the "Hellenic Academic Electronic (Text) books" project or submitted in the course of an open call for Open Access scientific content. The "Kallipos" repository aims at the organized presentation, storage and long-term preservation of open-access (text) books and learning objects for the academic and research community" [18]. Both eClass and Kallipos are resources that existed prior to the pandemic and were established and used in this new situation as well.

In some courses, Professors gave lectures in empty amphitheaters, wrote down notes on blackboards and everything was recorded using the OpenDelos Platform (http://opendelos.org/). "OpenDelos is an open-source platform for live streaming and recording video lectures commissioned by GUNET, the Greek Universities network" [19]. Students could watch the lectures in real time or later on demand, but with no interaction with the teacher.

Other courses were provided in real time, using a video conferencing platform. Professors used prior prepared digital material and/or online digital boards. Digital notes could be provided via the eClass platform and recorded video lectures via OpenDelos and/or YouTube. Students could interact with the Professor during the lesson.

During the academic year 2019-20 a study group was established to study mathematics teaching and learning at the university level (coordinated by Professor Despina Potari, a mathematics education researcher). The first two authors were members of this group. When the pandemic arose and remote learning was implemented, new questions sprung that needed to be answered. During the academic year 2020-21 the meetings and the discussions continued while the University community was better prepared to organize distance learning courses. All courses had both synchronous and asynchronous teaching methods and students could communicate with the Professor in video conferencing platforms.

\section{RESEARCH QUESTIONS}

The coronavirus pandemic gave Researchers the opportunity to investigate questions related to ERT, a newly explored field, based on the theoretical background and on the issues that emerged in these special circumstances. When the questionnaire was elaborated, we used the term "distance learning" to address questions related to ERT, in order to facilitate its comprehension by the participants. The terms "distance learning" and "e-learning" are used interchangeably when referring to ERT, thereafter in the present paper. The questionnaire was based on the following research questions:

1) How feasible is it for students to participate in distance learning lessons in terms of technical means, experience they already had and prior training in elearning?

2) How did students use the eClass service?

3) What are the advantages and disadvantages of distance education according to the students' opinion?

4) Between distance and face to face learning, which one do students prefer?

5) How did students evaluate forms of distance learning?

6) How did "Students' work status" affect their study?

7) How is "Preferred method of learning" (e-learning, face to face or both) associated with "Time spent on studying", "Frequency of attending courses", and "Previous experience in e-learning"?

8) How is "Year of study" associated with "Previous experience in distance learning", "Preferred method of learning", "Better e-learning method for understanding - live teleconferences/recorded video lectures", "Time spent on studying"?

\section{MATERIALS AND MEthodS}

The survey's reference population consisted of the active students in the Department of Mathematics, a four-year bachelor degree at the National and Kapodistrian University of Athens (2110 individuals). The actual number of students was provided by the Internal Evaluation Group of the Department of Mathematics. The sample came up with a convenience sampling technique.

A structured and anonymous questionnaire was constructed and distributed electronically to the population, addressing the research problems that arose after studying the relevant literature. In order to analyze the attitudes, values and beliefs of the population of interest, quantitative methods of research were selected [20]. The research team took care of the respondents' anonymity and confidentiality [21].

The questionnaire consisted of two parts. The first part included demographic questions and the second part questions concerning factors related to the emergency remote teaching that took place in March 2020, when the National and Kapodistrian University of Athens cancelled 
on-campus courses and students started using e-learning platforms (synchronous and asynchronous). Almost all questions were closed-ended but there were some openended questions for gathering additional information and letting students give their opinion [22].

Overall, 52 variables were coded. The statistical package SPSS (Statistical Package for Social Sciences Ver. 27) was used to perform statistical analysis. The association between different variables was tested using the $\chi^{2}$ independence test and coefficient Cramer's V. For significance level a $=0.05$, a result was considered statistically significant when $\mathrm{p}$ value $<0.05$ [23]. In order to ensure its consequence and the stability of results, the internal consistency reliability technique was applied for a group of variables used in the analysis. The Cronbach's alpha coefficient was 0.78 .

\section{RESULTS}

\section{A. Participants' Profile}

The sample consisted of 391 students. Their basic demographic characteristics are presented in Table I.

\begin{tabular}{|c|c|c|}
\hline & $\mathrm{N}$ & $(\%)$ \\
\hline \multicolumn{3}{|l|}{ Gender } \\
\hline Male & 173 & $44.2 \%$ \\
\hline Female & 218 & $55.8 \%$ \\
\hline \multicolumn{3}{|l|}{ Year of study } \\
\hline $1^{\text {st }}$ Year & 45 & $11.5 \%$ \\
\hline $2^{\text {nd }}$ Year & 73 & $18.7 \%$ \\
\hline $3^{\text {rd }}$ Year & 66 & $16.9 \%$ \\
\hline $4^{\text {th }}$ Year & 73 & $18.7 \%$ \\
\hline Exceeded the $4^{\text {th }}$ Year & 134 & $34.3 \%$ \\
\hline \multicolumn{3}{|l|}{ Living in Athens } \\
\hline No & 62 & $15.9 \%$ \\
\hline Yes & 329 & $84.1 \%$ \\
\hline \multicolumn{3}{|l|}{ Working } \\
\hline No & 219 & $56 \%$ \\
\hline Yes & 172 & $44 \%$ \\
\hline \multicolumn{3}{|l|}{ Technological Means } \\
\hline Pc with internet & 286 & $73.1 \%$ \\
\hline Pc with internet with others & 92 & $23.5 \%$ \\
\hline Smartphone with data & 13 & $3.3 \%$ \\
\hline
\end{tabular}

Most of the participants were women $(55.8 \%)$ and the vast majority of the participants were living in Athens $(84.1 \%)$. Regarding their year of study, $34.3 \%$ of the participants exceeded the $4^{\text {th }}$ Year and only $11.5 \%$ were first year students. Almost half of them had a job (44\%) and $73.1 \%$ were using their own computer with internet connection. We found that only $1.3 \%$ of the participants couldn't attend distance learning courses because of lack of technical means, whereas $62.1 \%$ could regularly attend courses since they had no technical problems. Most of the students $(86.4 \%)$ had no previous experience in e-learning, but the majority of them $(80.6 \%)$ stated they didn't need training to attend distance learning courses. We note that Greek students have been taught Informatics in Secondary Education for at least 4 years, and most of them are familiar with ICT. However, this does not guarantee their familiarity with e-learning platforms.

\section{B. Data Description}

During the e-learning period, $68.5 \%$ of the students responded that they used other resources in addition to those provided for the courses- which they had never used before. Those who used further resources watched mostly "videos on the internet", used "open-source material" such as that provided by the Kallipos platform, and some of them visited Mathematical sites.

Students and teachers used mostly eClass, the platform provided by the University, as described above. During the e-learning period students connected to eClass everyday $(50.6 \%)$ or five times a week $(32.7 \%)$, whereas prior to the pandemic only $18.2 \%$ connected every day, $24.3 \%$ five times, 26,1\% 3 times and 28.9\% 1-2 times a week (see Fig. 1). As for the use of the available features of the eClass platform, they found "very useful" and "extremely useful" the choices "Documents" (83.6\%) and "Announcements" $(77,8 \%)$, on the contrary the found "least useful" and "slightly useful" the choices "Chat" (67.5\%), "Messages" (55.8\%), "Discussions" (65.5\%) and "Wall" (71.4\%).
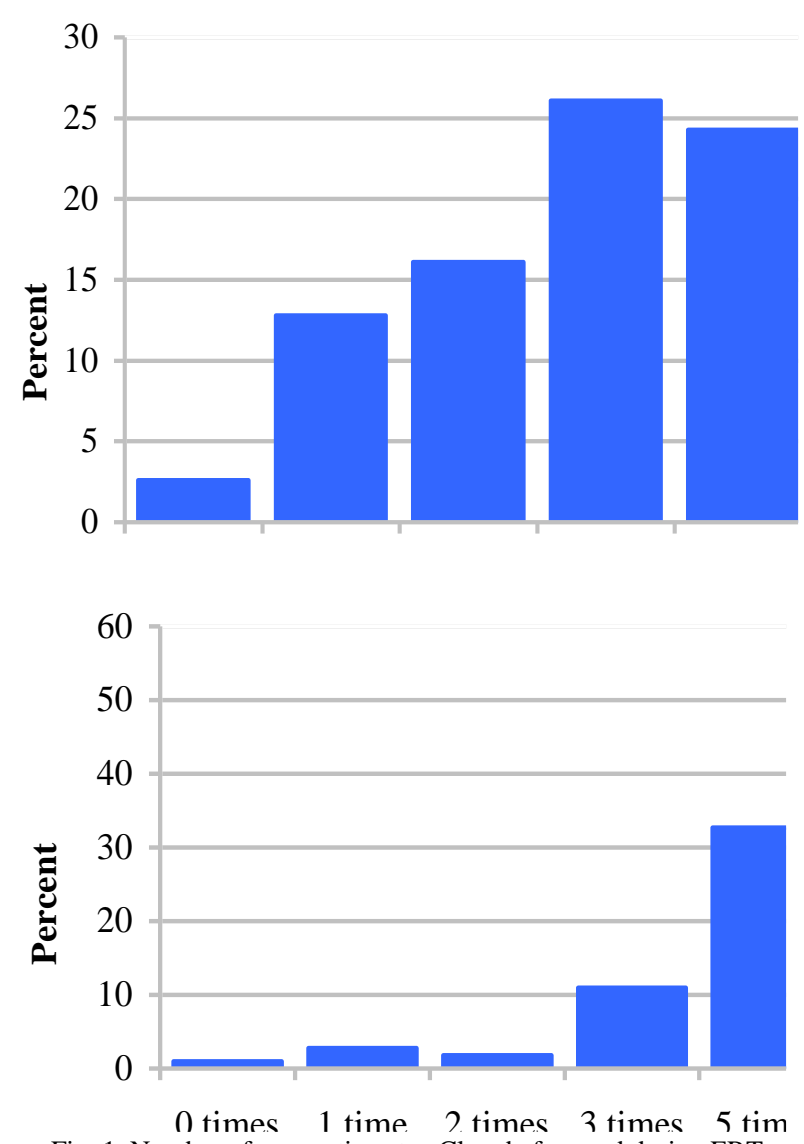

Fig. 1. Number of connections to eClass before and during ERT.

In the question "Which method of distance learning helped you better understand the course subject", $62.4 \%$ of the students answered: "Recorded video lectures" and 37.6\% "Live teleconferences".

In regard to "Recorded video lectures" choice, the supporting arguments, given by students in open ended questions, are summarized as follows: A) Students had the flexibility of time, that is, they were able to watch the recorded video lectures at a time that was more convenient to them. B) They could watch the video more than once, forward or rewind it. In this way, they could learn at their own pace, getting back to rewatch the lecture when they realized that they had misconceptions, having adequate time to take notes or refresh key concepts before the exams. C) 
They had fewer technical problems and difficulties than they had when live streaming, most of them because of poor network or inadequate hardware. D) Lastly, they argue that courses were more organized in the "Recorded video lectures" form. Specifically, they claim that lectures of this form had more coherence and were more comprehensive.

In regard to the "Live teleconferences" choice, the students' supporting arguments are summarized as follows: A) As the most important advantage of "Live teleconferences" students indicate the immediate communication between the teacher and the student, but also among peers. This form of distant lecturing was able to maintain the "question-answer" teaching practice and so gave them the certainty of understanding. B) The lectures were more interactive, making them feel closer to the real classroom. C) Scheduled live lectures helped them sustain the consistency in attending courses. D) Students were more focused during lectures because they weren't recorded. E) Teaching was adapted to the audience's needs in terms of speed, explanations, and examples.

In the question "How often did you attend distance learning courses in comparison to prior on-campus courses", $36.3 \%$ of the students answered "more often", $29.7 \%$ "as often", $20.7 \%$ "less often" and $13.3 \%$ "depending on the course". $47.6 \%$ of the students stated that they studied more when attending distance learning courses in comparison to prior on-campus, $30.4 \%$ the same and $22 \%$ less. Concerning the disadvantages of distance learning courses, students' answers are shown in Table II.

TABLE II: DisAdVANTAges of DistANCE LEARNING COURSES

\begin{tabular}{lccccc}
\hline & SI & LI & I & VI & EI \\
\hline $\begin{array}{l}\text { Lack of technical } \\
\text { means for students }\end{array}$ & $11.3 \%$ & & $16.9 \%$ & 20.5 & $37.9 \%$ \\
$\begin{array}{l}\text { Lack of communication } \\
\text { during the lesson }\end{array}$ & $6.6 \%$ & $11.5 \%$ & $23 \%$ & $27.1 \%$ & $31.7 \%$ \\
$\begin{array}{l}\text { Difficulties in } \\
\text { understanding }\end{array}$ & $10.7 \%$ & $16.1 \%$ & $23.5 \%$ & $26.9 \%$ & $22.8 \%$ \\
$\begin{array}{l}\text { Difficulties in } \\
\text { organization of study }\end{array}$ & $24.8 \%$ & $18.7 \%$ & $23.5 \%$ & $16.1 \%$ & $16.9 \%$ \\
$\begin{array}{l}\text { Incomplete technical } \\
\text { organization of courses }\end{array}$ & $8.7 \%$ & $13.6 \%$ & $21.2 \%$ & $26.3 \%$ & $30.2 \%$ \\
\hline $\begin{array}{l}\text { SI: Slightly Important, LI: Little } \\
\text { Important, EI: Extremely Important. }\end{array}$ & & & &
\end{tabular}

Other disadvantages that the students mentioned were "lack of communication with other students", "lack of sociability", "not readable notes from teachers", "too many hours in front of a computer", "speed of lectures", "difficulties in concentration".

Concerning the advantages of distance learning courses, students' answers are summarized in Table III.

TABLE III: ADVANTAGES OF DISTANCE LEARNING COURSES

\begin{tabular}{lccccc}
\hline \hline & SI & LI & I & VI & EI \\
\hline $\begin{array}{l}\text { Flexibility in time } \\
\text { and space }\end{array}$ & $4.3 \%$ & $6.4 \%$ & $13.6 \%$ & $13 \%$ & $62.7 \%$ \\
$\begin{array}{l}\text { Creation of new } \\
\text { learning material }\end{array}$ & $11 \%$ & $14.1 \%$ & $23.3 \%$ & $21.2 \%$ & $30.4 \%$ \\
$\begin{array}{l}\text { Didactic use of } \\
\text { technical means }\end{array}$ & $12.3 \%$ & $16.6 \%$ & $25.6 \%$ & $23 \%$ & $22.5 \%$ \\
$\begin{array}{l}\text { Watching recorded } \\
\text { lectures more times } \\
\text { Better organization } \\
\text { of teaching }\end{array}$ & $2.8 \%$ & $2.3 \%$ & $9 \%$ & $16.9 \%$ & $69.1 \%$ \\
\hline
\end{tabular}

SI: Slightly Important, LI: Little Important, I: Important, VI: Very Important, EI: Extremely Important.
For the question "What would you choose: e-learning or face to face courses" (when all methods can be applied), $26.6 \%$ of the students answered "face to face", $26.6 \%$ "elearning" and $46.8 \%$ "a combination of both". Their open answered (excerpts) reasoning is recorded in Table IV.

TABLE IV: REASONS FOR PREFERRING "FACE TO FACE", "E-LEARNING" OR “A COMBINATION OF BOTH” METHODS OF LEARNING

-Direct communication with teachers and colleagues, immediacy

-Better organization of study

- Better concentration in class

o -They can ask questions and discuss what they can't understand

8 -Learning and understanding are better

¿ -Distance learning is tedious, as the lesson is done at a faster

pace

\& -Sometimes there are technical problems

-University is a place of socializing and exchanging of ideas -

Need for interaction in university

-Learning is not a personal matter

-Can't afford technical equipment

-Can't work for many hours in front of a computer

-Flexibility in time and place

-It is better when classroom is full of students

-Safer in the COVID-19 era

-No wasted time (commuting)

ङ -You do not always have the opportunity to ask questions

II -Can't attend classes because they are working

-Studying material always available

-It is better when living in another city

-Depending on the course and teacher

- It is better "face to face" and thereinafter to have the lectures

on recorded video

-E-learning is better for theory and "face to face" is better for labs.

In regard to face-to-face learning, students acknowledge as most important the factors of communication, socializing, and stability in the learning process, while they exclude "distance learning" because of the lack of means in proper hardware equipment or network problems (accessibility). Regarding communication aspects, students who chose face-to-face learning claim that this form helps them to keep a constant communication with teachers and peers which is an important aspect in their understanding because of the immediate "question-answer" interplay. They, also, state that socializing is a central aspect of the learning process with important psychological and motivational consequences in their study. Personal relationships and interaction are needed not only as a teaching practice but also as a way of exchanging ideas and key values among peers in order to create a community. As for stability, they claim that face to face learning helps them more to stay focused in lectures and maintain a routine in their study schedule which contributes to organizing their study better. In this direction, they exclude distance learning due to the difficulty of studying on a computer for many hours because of exhaustion. In this view we can recognize the communicational and social characteristics of acquiring knowledge that students need but also a negation or a hesitation about using new digital practices in the teaching and learning process.

Regarding e-learning, students seem to consider safety issues of high priority due to the COVID-19 danger of 
infection. At that time pandemic was at its beginning and dominated the public discourse, so many argued in favour of distance learning because of the fear of infection for them or their families. Nonetheless, the majority of answers were about teaching matters. Mainly, the supporting arguments are in alignment with the advantages students recognize in this form, that is, flexibility of time, repetition of recorded lectures, more study resources, preexisting insufficient financial resources and better organization of their study. An interesting remark here is that none of the students who chose distance learning excluded the face-toface form, except for reasons related to the pandemic. In contrast to students who chose face-to-face learning, those who chose e-learning do not oppose to the traditional method of lecturing but evaluate it independently in a positive way.

As for the combination of both options, in general, participants concede the advantages of both methods by giving equal credits in regard to the individual needs of each student. Firstly, in terms of technology in education and accessibility, they recognize the importance of digitalization of the learning process but are also skeptical about the students' accessibility to the suitable means. Secondly, they argue for flexibility, but on the other hand acknowledge the consequences that alternative methods to face to face have on communication and socializing. Flexibility offers an individualized context of learning by supporting students with a. financial issues, b. far away residence, c. common hours of lecturing for different courses, d. classes with big audiences or e. working hours conflicts. At the same time, they express the significance of personal relations and "question-answer" interplay as essential factors for a deeper understanding. By recognizing the different needs of each individual, they suggest a combination of both types, in which lectures are live but recorded in order to be available for students to watch them later in the form of a recorded video. Supporting this argument, it is worth mentioning a dichotomy regarding which method is more appropriate for better organization of the study. So, this choice was made by students with different views, that is, students who believe that distance learning helped them organize their study and notes and on the other hand students who had big difficulties to deal with the flexibility and freedom that this form of learning provides. Students' evaluation of different forms of elearning is reported in Table $\mathrm{V}$.

TABLE V: EVALUATION OF FORMS OF E-LEARNING

\begin{tabular}{lccccc}
\hline \hline & $\mathrm{VP}$ & $\mathrm{P}$ & $\mathrm{F}$ & $\mathrm{G}$ & $\mathrm{E}$ \\
\hline $\begin{array}{l}\text { No teaching, simple } \\
\text { posting notes / exercises. }\end{array}$ & $58.1 \%$ & $23.8 \%$ & $12.3 \%$ & $4.6 \%$ & $1.3 \%$ \\
$\begin{array}{l}\text { Teaching using recorded } \\
\text { video lectures } \\
\text { (asynchronous) }\end{array}$ & $8.7 \%$ & $17.6 \%$ & $25.6 \%$ & $22 \%$ & $26.1 \%$ \\
$\begin{array}{l}\text { Teaching through a } \\
\text { platform (webex, skype } \\
\text { etc.) with digital notes } \\
\text { and presentation by the } \\
\text { teacher (synchronous). }\end{array}$ & $6.4 \%$ & $9.5 \%$ & $24 \%$ & $29.2 \%$ & $30.9 \%$ \\
$\begin{array}{l}\text { Teaching through a } \\
\text { platform (webex, skype } \\
\text { etc.) using digital board } \\
\text { by the teacher } \\
\text { (synchronous) }\end{array}$ & $5.9 \%$ & $7.7 \%$ & $18.4 \%$ & $27.4 \%$ & $40.7 \%$ \\
\hline VP: Very Poor, P. Poor, F. Fair, G: Good, E. Excell & & & & & \\
\hline
\end{tabular}

VP: Very Poor, P: Poor, F: Fair, G: Good, E: Excellent.

\section{Statistical Tests}

In order to answer the research questions mentioned earlier, we examined if several correlations are worth mentioning.

As expected, $72.7 \%$ of the students who were working preferred recorded video lectures over live teleconferences instead of $54.3 \%$ of those not working. We found a correlation $\left(\chi^{2}=13.806\right.$, df $=1, p$-value $=0.000<0.05 /$ Cramer's V $=0.188, \mathrm{p}=0.000<0.05$ ) between "Better elearning method for understanding" (live teleconferences or recorded video lectures) and "Having a job". At the same time $46.5 \%$ of the students who were working studied more often than before emergency distance learning. We found a correlation $\left(\chi^{2}=15.803\right.$, df $=3$, p-value $=0.001<0.05$ / Cramer's $\mathrm{V}=0.201, \mathrm{p}=0.001<0.05$ ) between "Frequency of attending classes in distance learning compared to face-toface (prior to the pandemic)" and "Having a job".

Also, students who stated that they need training for attending distance learning courses seem to attend classes less frequently than before emergency distance learning, compared to those that answered they didn't need training. Moreover, $72.4 \%$ of the students who needed training in distance learning believed that recorded video lectures are more useful in understanding content than live teleconference lectures, whereas $60 \%$ of those who didn't need training believed the same. There is a correlation $\left(\chi^{2}=\right.$ 3.992, df $=1$, p-value $=0.046<0.05 / \mathrm{Phi}>0.10$, $\mathrm{p}=0.046<0.05)$ between the "Need for training in elearning" and the choice of "Better e-learning method for understanding, live teleconference or recorded video lectures".

As indicated in Table VI, $50.5 \%$ of the students who studied more in distance learning during the pandemic and $49.6 \%$ of the students who studied the same, preferred a combination of both methods (face to face, e-learning). On the other hand, $54.7 \%$ of those who studied less in elearning choose face to face classes.

In order to determine whether students' "Preferred method of learning" - between distance education, face to face and both - is associated with other variables, we examined if several correlations are worth mentioning. As shown in Table VII, we found that "Preferred method of learning" is associated with a correlation $\left(\chi^{2}=52.475\right.$, df $=4$, $\mathrm{p}$-value $=0.000<0.05 /$ Cramer's $\mathrm{V}=0.259>0.25$, $\mathrm{p}$ value $=0.00<0.05)$ with "Differences in time spent on studying", a correlation $\left(\chi^{2}=114.492, \mathrm{df}=6\right.$, pvalue $=0.000<0.05 /$ Cramer's $\mathrm{V}=0.383>0.25$, pvalue $=0.00<0.05$ ) with "Frequency of attending classes in distance learning compared to face-to-face (prior to the pandemic)", a correlation $\left(\chi^{2}=9.584\right.$, df $=2, \mathrm{p}$ value $=0.008<0.05 /$ Phi $0.157>0.15, \mathrm{p}=0.008<0.05)$ with "Previous experience in e-learning" and a correlation $\left(\chi^{2}=\right.$ 29.019, df $=8$, p-value $=0.000<0.05 /$ Cramer's $V=0.193$, $\mathrm{p}=0.000<0.05$ ) with "Year of study".

As it was expected, students preferring the face-to-face method attended classes less often and those preferring the "E-learning" method attended classes more often (see Fig. 2).

Moreover, students with no experience in e-learning preferred the "E-learning" method the least (see Fig. 3). 


\begin{tabular}{|c|c|c|c|c|c|c|}
\hline & & & \multicolumn{3}{|c|}{$\begin{array}{l}\text { Preferred method between e-learning face to face } \\
\text { or combination of both }\end{array}$} & \multirow[t]{2}{*}{ Total } \\
\hline & & & Face-to-face & E-learning & Combination of Both & \\
\hline \multirow{5}{*}{$\begin{array}{l}\text { Differences in time } \\
\text { spent on studying } \\
\text { (DTSS) }\end{array}$} & & Count & 47 & 9 & 30 & 86 \\
\hline & Studying less & $\%$ within DTSS & $54,7 \%$ & $10,5 \%$ & $34,9 \%$ & $100,0 \%$ \\
\hline & & Count & 30 & 30 & 59 & 119 \\
\hline & Studying the same & $\%$ within DTSS & $25,2 \%$ & $25,2 \%$ & $49,6 \%$ & $100,0 \%$ \\
\hline & & Count & 27 & 65 & 94 & 186 \\
\hline \multirow{3}{*}{ Total } & Studying more & $\%$ within DTSS & $14,5 \%$ & $34,9 \%$ & $50,5 \%$ & $100,0 \%$ \\
\hline & & Count & 104 & 104 & 183 & 391 \\
\hline & & $\%$ within DTSS & $26,6 \%$ & $26,6 \%$ & $46,8 \%$ & $100,0 \%$ \\
\hline
\end{tabular}

TABLE VII: CORRELATION OF “PREFERRED METHOD OF LEARNING” AND OTHER VARIABLES

\begin{tabular}{lcccc}
\hline \hline & $\chi^{2}$ & df & p-value & $\begin{array}{c}\text { Cramer's } \\
\text { V or Phi } \\
\text { value and } \\
\text { p-value }\end{array}$ \\
\hline $\begin{array}{l}\text { Differences in time spent on } \\
\text { studying }\end{array}$ & 52.475 & 4 & 0.000 & 0.259 \\
$\begin{array}{l}\text { Frequency of attending classes } \\
\text { in distance learning compared } \\
\text { to face-to-face }\end{array}$ & 114.492 & 6 & 0.000 & 0.383 \\
$\begin{array}{l}\text { Best method for understanding, } \\
\text { live teleconference or recorded } \\
\text { video lectures }\end{array}$ & 0.540 & 2 & 0.764 & $\begin{array}{c}\text { No } \\
\text { correlation }\end{array}$ \\
$\begin{array}{l}\text { Previous experience in e- } \\
\text { learning }\end{array}$ & 9.584 & 2 & 0.008 & 0.517 \\
Year of study & 29.019 & 8 & 0.000 & 0.193 \\
\hline \hline
\end{tabular}

\section{Preferred method of learning}

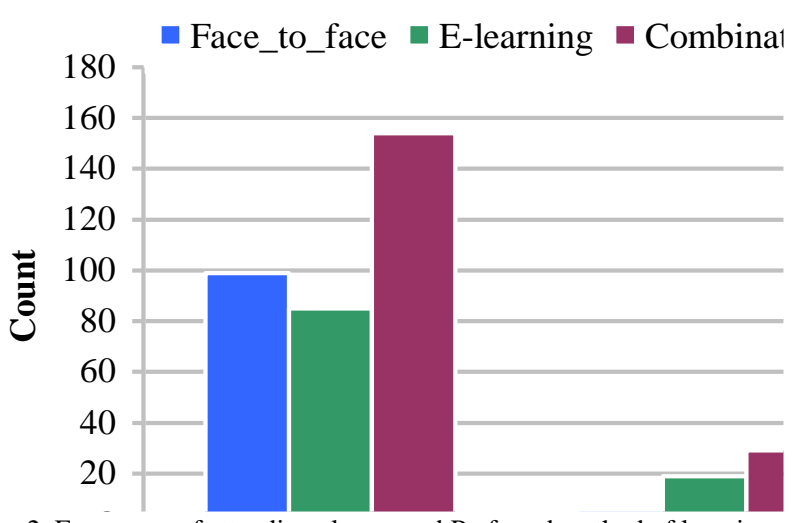

Fig. 2. Frequency of attending classes and Preferred method of learning.

\section{Frequency of attending classes during learning and prior to the pandemic}

$\square$ depends on the lesson $\square$ less often $\square$ as often $\square$ mor

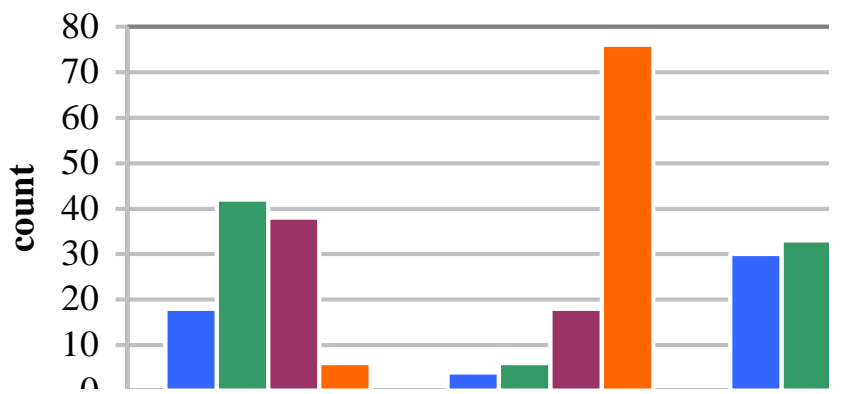

Fig. 3. Preferred method of learning and Previous experience in e-learning.

$22.4 \%$ of the students who had exceeded their $4^{\text {th }}$ year of study had previous experience in distance learning. But only $11 \%$ of the seniors, $9.1 \%$ of the juniors, $11 \%$ of the sophomores and $2.2 \%$ of the freshmen had previous experience in distance learning. We noticed a correlation $\left(\chi^{2}\right.$ $=15.817, \mathrm{df}=4, \mathrm{p}$-value $=0.003<0.05 /$ Cramer's $\mathrm{V}=0.201$, $\mathrm{p}=0.003<0.05)$ between "Previous experience in distance learning" and the "Year of study." (See Fig. 4).

\section{Previous experience in e-learning}

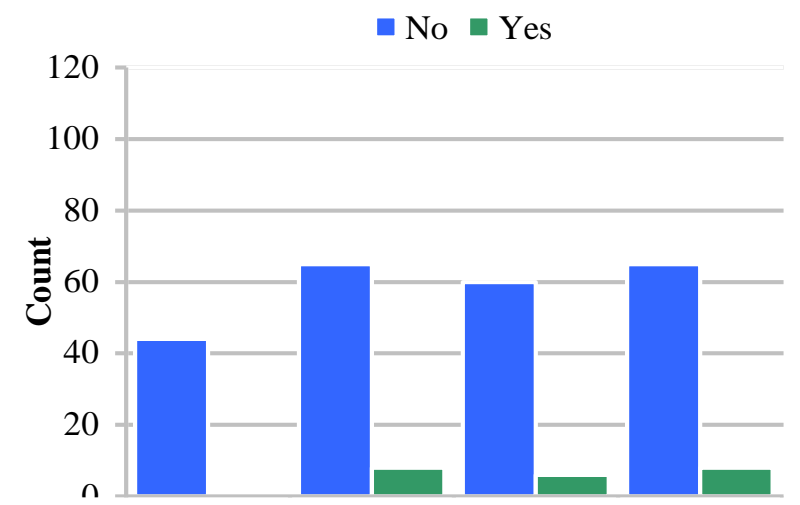

Fig. 4. Previous experience in distance learning and year of study.

As shown in Fig. 5. students in the first two years of study $(77.8 \%$ and $74 \%)$ and those exceeding their 4 th year of study $(63.4 \%)$ preferred recorded video lectures rather than live teleconferences but those in their 3rd and 4th year preferred live teleconferences and recorded video lectures to the same degree. There is a correlation $\left(\chi^{2}=17.541, \mathrm{df}=4\right.$, $\mathrm{p}$-value $=0.002<0.05 /$ Cramer's $\mathrm{V}=0.212, \mathrm{p}=0.002<0.05)$ between "Year of study" and "Better e-learning method for understanding" (Live teleconferences or Recorded video lectures).
Better e-learning method for understanding

- Use teleconference $\square$ Recorded video lectures

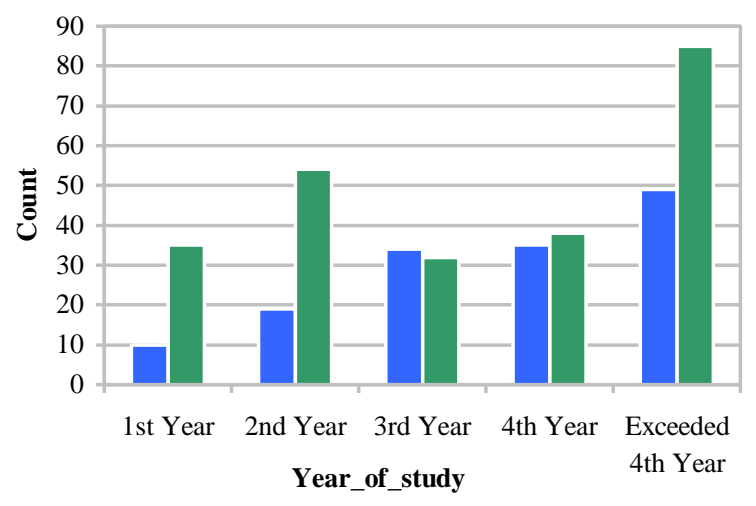

Fig. 5. Better e-learning method for understanding and year of study.

During the first period of lockdown due to COVID-19, students whose year of study exceeded the 4th, attended 
courses more often, in comparison to the time prior to the pandemic (see Fig. 6). We found a correlation $\left(\chi^{2}=63.672\right.$, df $=12, \quad p$-value $=0.000<0.05 /$ Cramer's $\mathrm{V}=0.233$, $\mathrm{p}=0.000<0.05)$ between "Year of study" and the "Frequency students attended e-learning courses compared to on campus ones prior to the pandemic".

Frequency of attending e-learning courses co to on-Campus ones (face to face) prior to pandemic

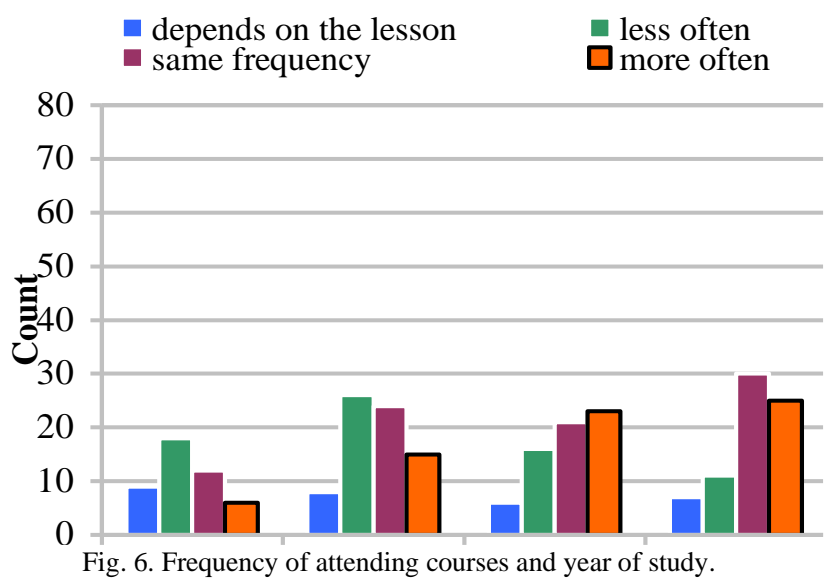

Moreover, at distance learning, as the year of study progresses, students are studying more compared to the period before emergency distance learning, (see Fig. 7). We observed a correlation $\left(\chi^{2}=29.558\right.$, df $=8$, pvalue $=0.000<0.05$ /Cramer's $V=0.194, \mathrm{p}=0.000<0.05$ ) between "Year of study" and the "Time students spent on studying" compared to the period before emergency distance learning.

\section{Time spent on studying during e-learni] compared to prior to the pandemic}

$\square$ less time $\square$ the same $\square$ more time

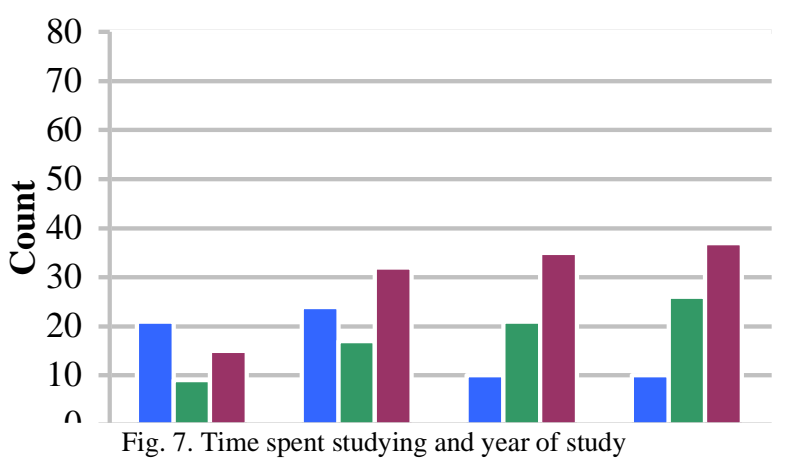

We also found a correlation $\left(\chi^{2}=29.019\right.$, df $=8$, pvalue $=0.000<0.05 /$ Cramer's $\mathrm{V}=0.193, \mathrm{p}=0.000<0.05)$ between "Year of study" and "Preference between face-toface learning, e-learning or both methods". Note in Fig. 8 that freshmen prefer face to face learning, while, as the year of study progresses, e-learning and combination of both methods seem more popular.

\section{Preferences between Face to face learning, $\mathbf{E}$} learning or Combination of both methods

- Face_to_face $\square$ E-learning $\square$ Combination of both

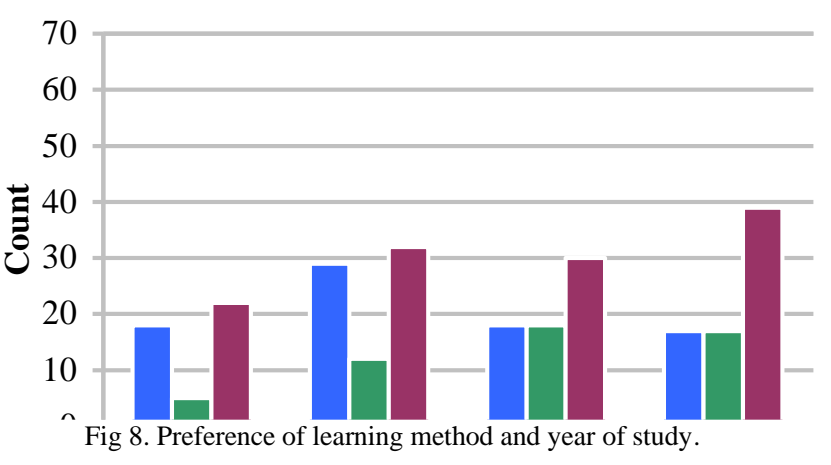

\section{DISCUSSION}

According to research data and the analysis we conducted, it was revealed that the vast majority of the students were able to participate in distance lessons. It is important to note that a significant percentage of the students had technical problems, due to lack of proper equipment or network failures. It is worth mentioning that in the COVID-19 emergency situation many of the network services worldwide, especially in the education field, malfunctioned. The same is mentioned in the paper of Kutluk \& Gulmez [12]. As for the previous experience that students had in distance learning or the training they possibly needed, research results revealed that despite the inexperience of most of them, the majority didn't consider as necessary a previous training in e-learning methods.

An interesting finding regarding the use of eClass is that an extreme utilization of the platform emerged as a solution for more educational resources due to the emergency of the COVID-19 situation. It is indicative that before the pandemic only $18.2 \%$ connected every day and $24.3 \%$ five times per week, instead of $50.6 \%$ and $32.7 \%$ afterwards. More specifically and with regard to eClass services, the majority of students evaluate the options of "Documents" and "Announcements" as extremely useful but as slightly useful the options of "Chat", "Messages", "Discussions" and "Wall". In our view, this doesn't mean that the latter are not useful but in the context of an emergency there was no proper time for adequate preparation in order to maximize the usefulness they can provide.

Concerning the advantages and disadvantages of distance learning that students reported, research results indicate various perspectives. As for the advantages, students primarily highlight the flexibility of time and place of studying. At a time when many students work, it is necessary for one to have the opportunity to use media and technical means in a way that respects contemporary social and financial demands. Another important advantage they recognize, which is related to the COVID-19 pandemic and the emergency aspect, is the safety that distance learning provides; many students were worried about their own and their family's health. Other advantages mentioned, related to the learning processes, were the creation of new elearning resources (over 70\% highlight it as important), the 
use of technical means in the teaching process (over $50 \%$ highlight it as important), better organization of teaching (over $78 \%$ highlight it as important). A significant feature that was highlighted as extremely important (over 69\%) was the possibility of watching a lecture again through recorded video courses. This was a highly significant asset that students made use of, because they could watch the same lecture as many times as they needed, during the semester or before the exams in order to take more detailed notes. In this way they could benefit from a process that matches with their own learning style. Last but not least, other worth mentioning features that students reported were the advantage of saving time from commuting to the University campus and a more comfortable environment, especially when actual classrooms are filled of students. Regarding the disadvantages of distance learning, more than $75 \%$ of the participants report the lack of means as important, more than $81 \%$ the lack of communication in e-learning lessons, more than $72 \%$ the difficulties in understanding the lecture, and more than $77 \%$ the fast adaptation of traditional courses with the use of new e-learning tools. As we mention above, the emergency of distance learning played a pivotal role in readiness of the whole teaching and learning process, mainly in terms of adequate equipment, proper communication tools and lesson structure modified for elearning. These findings are consistent with the research of Shim and Lee [11].

Some contradictions in students' perspectives become crystal-clear on the question about the preferred method between distance learning, face-to-face learning, or the combination of both. So, one may acknowledge the advantages of distance learning but rank higher the disadvantages it has along with the advantages of face-toface learning (e.g., consistent communication), which makes her/him choose face-to-face learning and vice versa.

The distribution of the students' answers also supports this argument with $26.6 \%$ choosing e-learning, $26.6 \%$ choosing face-to-face and $46.8 \%$ choosing the combination of both. In research results we summarized the justifications provided by the students for each option. Based on that, we suggest that even in the emergency context of COVID-19 in which e-learning occurred, the merits of both methods for students' learning and understanding are clear. A characteristic example of the relative benefits each method provides is the group of the students who work. As mentioned above, a considerable number of students work these days, so the need for flexibility in their studies prevails over the need for immediate communication, usually because of schedule overlay. To this direction, working students seem to prefer distance learning. Moreover, between the options of the "Recorded video lectures" and "live teleconferences" students answered $62.4 \%$ and $37.6 \%$ respectively. Once again, the advantage of flexibility in time and place, but also the benefits of a recorded lecture, dominate the need for communication or other advantages that live teleconference has. So, we interpret the effectiveness of each method through the lens of the usefulness that it may have according to the individual needs of students.

Students, when asked to evaluate the forms of e-learning, find very poor the form of only posting notes and exercises
(58.1\%) and excellent the form of using teleconference platforms and digital boards $(40.7 \%)$. Even though the majority of them answered that "recorded video lectures" helped them understand the lesson more than live teleconferences, the percentage that find it excellent was $26.1 \%$ less than other synchronous forms.

Concerning the preferred method of learning (face-toface, e-learning, both) related to the differences in time of study, it seems that students who are more receptive to elearning studied more, unlike those who preferred the faceto-face method that studied less during the period of remote emergency learning. As for the preferred method of learning related to previous experience in e-learning, we remark that students with no experience in e-learning preferred the "Elearning" method the least. Finally, concerning the preferred method of learning relative to frequency of attending classes (before and during e-learning), it revealed a tendency which indicates that the students who were more receptive to e-learning attended distance learning courses more often, in contrast to those who preferred face-to-face who attended the same or less often.

Concerning the year of study related to what students choose as the better e-learning method for understanding, (live teleconferences or recorded video lectures), the analysis revealed that the 1 st and 2 nd year students preferred recorded video lectures in a vast majority $(77.8 \%$ and $74 \%$ respectively), 3rd and 4 th year students are almost equally distributed and the students having exceeded their 4 th year show a preference in "recorded video lectures" $(63.4 \%)$. We also found a correlation between year of study and preferred method of learning, with the research results revealing a tendency in which as long as the year of study progressed the preference was orientated towards e-learning and the combination of both methods. Relating the year of study to the time students spent on studying, research results indicate that during ERT most of the students studied more. In addition, it revealed a tendency in which as the year of study progressed, the time students spent on studying increased. Finally, regarding the relation of year of study to previous experience in distance learning, it revealed that as the year of study advanced, more students had experience in distance learning; however, the vast majority of students at any year of study didn't have any significant previous experience.

\section{CONCLUSION}

The emergency of pandemic due to COVID-19 forced the whole educational community to take actions in order to maintain the teaching and learning process as close to normality as it could. Despite the issues that arose in this effort, with many inadequacies and failures which made the conduct of courses out of ordinary, a new horizon of opportunities emerged with the use of the available digital means. In this direction, we attempted to trace difficulties of Emergency Remote Teaching. Under certain circumstances, it seems that e-learning practices and methods in combination with the traditional face-to-face learning could set a new pattern in education which will include the individual characteristics and needs of every student. 
Findings of this research could help the University Community design teaching methods and prepare appropriate technical solutions in case e-learning is the only way, so that ERT can easily switch to planned distance learning education which would benefit every student. We suggest further inquiry in the field, after the second year of e-learning, combining both quantitative and qualitative research.

\section{ACKNOWLEDGMENTS}

The authors would like to thank the coordinator of the study group Professor Despina Potari and its members Professor Theodossios Zachariades and EDIP member Irene Deliyanni, who contributed to the realization of the questionnaire, with useful comments and remarks. We would also like to thank Professor Apostolos Burnetas (head of the Department during the time period under study, Professor Aristides Kontogeorgis (head of the Department during the academic year 2020-21) and Professor Despina Potari for reading this paper and making useful suggestions. We thank the anonymous referee for his useful comments and recommendations. Last but not least, we would like to thank all Students who participated in the survey for this research and gave us the opportunity to write this paper.

\section{REFERENCES}

[1] Schlesselman L. S. Perspective from a teaching and learning center during emergency remote teaching. American Journal of Pharmaceutical Education, Aug. 2020;84(9):11-29.

[2] Wang G., Zhang Y., Zhao J., Zhang J., and Jiang F. Mitigate the effects of home confinement on children during the COVID-19 outbreak. The Lancet, March 2020;395(10228):945-947.

[3] Hodges C., Moore S., Lockee B., Trust T., and Bond A. The difference between emergency remote teaching and online learning. Educause Review, March 2020; 27(1):1-9.

[4] UNESCO.COVID-19 Educational disruption and response. 2020. [Online]. Available: https://en.unesco.org/covid19/educationresponse

[5] UNESCO. Global education coalition. 2020b. [Online]. Available: https://en.unesco.org/covid19/educationresponse/globalcoalition

[6] Bozkurt A. and Sharma R. C. Emergency remote teaching in a time of global crisis due to CoronaVirus pandemic. Asian Journal of Distance Education, 2020;15(1): i-vi.

[7] Affouneh S., Salha S. and Khlaif Z. N. Designing quality e-learning environments for emergency remote teaching in coronavirus crisis. Interdisciplinary Journal of Virtual Learning in Medical Sciences, June 2020;11(2):135-137.

[8] Coeckelbergh M. The postdigital in pandemic times: A comment on the Covid-19 crisis and its political epistemologies. Postdigital Science and Education, 2020;2(3):547-550.

[9] Kedraka K. and Kaltsidis C. Effects of the Covid-19 Pandemic on University Pedagogy: Students' experiences and Considerations. European Journal of Education Studies, 2020;7(8):17-30. doi: http://dx.doi.org/10.46827/ejes.v7i8.3176.

[10] Chung E., Subramaniam G., and Dass L. C. Online Learning Readiness among University Students in Malaysia amidst COVID19. Asian Journal of University Education, 2020;16(2):46-58.

[11] Shim T. E. and Lee S. Y. College students' experience of emergency remote teaching due to COVID-19. Children and Youth Services Review, Dec. 2020;119: 1-7, article 105578.

[12] Kutluk F. A. and Gulmez M. A research about distance education students' satisfaction with education quality at an accounting program. Procedia-Social and Behavioral Sciences, May 2012;46:2733-2737.

[13] Iglesias-Pradas S., Hernández-García Á., Chaparro-Peláez J., and Prieto J. L. Emergency remote teaching and students' academic performance in higher education during the COVID-19 pandemic: A case study. Computers in Human Behavior, June 2021;119:article 106713.
[14] Jena P. K. Impact of Covid-19 on higher education in India. International Journal of Advanced Education and Research, June 2020;5(3):77-81.

[15] Tarkar P. Impact of Covid-19 Pandemic on Education System. International Journal of Advanced Science and Technology, 2020;29(9):3812-3814.

[16] Schleicher A. The impact of COVID-19 on education - Insights from Education at a Glance. OECD, 2020. [online]. Available: https://www.oecd.org/education/the-impact-of-covid-19-oneducation-insights-education-at-a-glance-2020.pdf.

[17] Open eClass. Platform Description. Retrieved from Open eClass Platform, 2021. [Online]. Available: https://docs.openeclass.org/en/3.10/detail_description.

[18] Hellenic Academic Ebooks. 2021. [Online]. Available: https://repository.kallipos.gr/?locale=en.

[19] Open Delos. 2021. [Online]. Available: http://opendelos.org/?page_id=21462\&lang=en.

[20] Robson C. and McCartan K. Real World Research, John Wiley \& Sons, 2016

[21] Cohen L., Manion L., and Morrison K. Research Methods in Education (In Greek), Athens: Metaixmio, 2008.

[22] Siniscalco M. T., Auriat N. "Questionnaire design," in Quantitative research methods in educational planning, Ed. Ross KN, Paris: UNESCO International Institute for Educational Planning, Paris, 2005 , mod. 8

[23] Apostolakis I. and Stamouli A. Validity and reliability assessment of quantitative research questionnaires in health units: The case of a questionnaire concerning the evaluation of a nursing services management information system of a hospital. Statistical Review, 2006;2(1):3-25

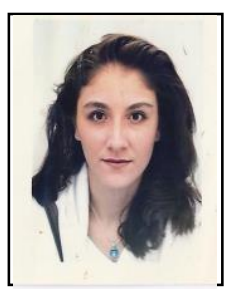

Margarita Karaliopoulou was born in Athens. She obtained a degree in Mathematics from University of Patras in 1991, an MSc in Informatics and Operational Research in 1993, an MSc in Statistics and Operational Research in 2004 and a PhD from National and Kapodistrian University of Athens, with a dissertation entitled "Discrete Semi-Markov Procedures and applications in word Occurrences".

She has worked for several years as a teacher of Informatics in secondary education. Since November 2017, she has been an EDIP member (discipline: Probability and Statistics) of the Department of Mathematics at the National and Kapodistrian University of Athens. Author of a book and several papers in journals and conference proceedings, among which the paper entitled "On Discrete Time SemiMarkov Chains and Applications in Words Occurrences" Communications in Statistics-Theory and Methods. 37(8) 1306-1322 (Chryssaphinou O., Karaliopoulou M and Limnios N.).

Dr Karaliopoulou is an elected member of the board of directors of PAPEDE (Panhellenic Association of Secondary education), member of the HMS (Hellenic Mathematical Society), and cofounder and former member of the board of directors of PEKAP (Panhellenic Association of teachers in Informatics).

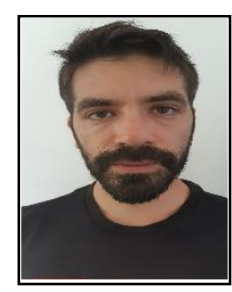

Yiorgos Mavrommatis was born in Athens, Greece. He obtained a degree in Mathematics in 2015 and a MSc in Mathematics Education in 2019 from National and Kapodistrian University of Athens. Currently, he is a PhD candidate in Mathematics at the Education at National and Kapodistrian University of Athens.

He has worked for many years in informal education, by creating and implementing educational programmes oriented to STEAM interdisciplinary. Author of several papers publicised in the H.M.S. and En.E.Di.M. Greek conferences. He is currently a teacher of Mathematics in secondary education.

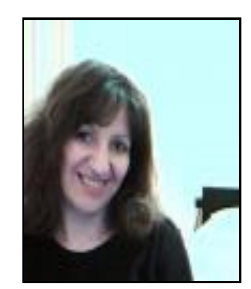

Georgia Menounou was born in Peloponnesus Greece. She graduated with the bachelor degree on Information Science and Technology from the Athens University of Economics and Business in 1993. She received a MED Degree from the Hellenic Open University in 2015.

She worked as a system and network administrator in the private sector and as a project manager in many EU and company projects. She also worked for several years as a teacher of Informatics in secondary education. She is currently responsible for supporting schools and teachers 
to implement ICT (Information Computer Technology) in teaching. Her research focuses mainly on the educational aspects of informatics.

Ms. Menounou is a member of PEKAP (PanHellenic Association of Teachers in Informatics) and of PAPEDE (PanHellenic Pedagogical Society for Secondary Education).

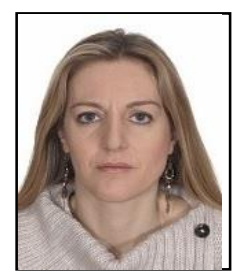

Stavroula Pantelopoulou was born in Kalamata, Greece. She obtained a degree in Informatics from the University of Piraeus in 1998, an MSc in Information Technology Management from the University of Sunderland in 2005, an MSc in Educational Technology and Human Resources Management from the National and Kapodistrian University of Athens in 2011 and a $\mathrm{PhD}$ from the from National and Kapodistrian University of Athens with a thesis entitled "The assessment of Secondary and Higher Education in Greece and England. A comparative, historical, institutional and ideological approach. [Period: 1974-2013]".

She worked as a developer, analyst and project manager in various retail, public sector and banking projects, and as an $R \& D$ analyst in the banking sector. She was a tutor in Piraeus University of Applied Science. She is currently a teacher of Informatics in secondary education (serving as Consultant $\mathrm{A}$ at IEP). She published more than 15 articles in various scientific journals and international conference proceedings. She is a Reviewer of Emerald's journal "The Learning Organization".

Dr Pantelopoulou is a member of PEKAP (PanHellenic Association of Teachers in Informatics), of PAPEDE (Panhellenic Association of Secondary Education), of O.E.E (Economic Chamber of Greece) and of E.E.P.E.K (Scientific Association for the Promotion of Educational Innovation). 